\title{
A Multilayer Soil Moisture Dataset Based on the Gravimetric Method in China and Its Characteristics
}

\author{
AIHUI WANG \\ Nansen-Zhu International Research Centre, Institute of Atmospheric Physics, Chinese Academy of Sciences, \\ Beijing, China \\ XUELI SHI \\ National Climate Center, China Meteorological Administration, Beijing, China
}

(Manuscript received 11 February 2019, in final form 19 June 2019)

\begin{abstract}
Based on the gravimetric-technique-measured soil relative wetness and the observed soil characteristic parameters from 1992 to 2013 in China, this study derives a user-convenient monthly volumetric soil moisture (SM) dataset from 732 stations for five soil layers $(10,20,50,70$, and $100 \mathrm{~cm})$. The temporal-spatial variations in SM and its relationship with precipitation (Pr) in different subregions are then explored. The magnitude of SM is relatively large in south China and is low in northwest China, and it generally increases with soil depth in each region. The maximum SM appears in spring and/or autumn and the minimum in summer, and the SM seasonality does not vary as distinctly as that of Pr. For the top three soil layers (10-, 20-, and 50-cm levels), the linear trend analysis indicates an overall increasing SM tendency, and the mean trends (averaged across stations with trends passing a $95 \%$ significance level test) are $9.35 \times 10^{-7}, 7.37 \times 10^{-3}$, and $2.45 \times$ $10^{-3} \mathrm{~cm}^{3} \mathrm{~cm}^{-3} \mathrm{yr}^{-1}$, respectively. SM memory depends on the soil depth and regions, and it has longer retention time in the deeper layers. Furthermore, the correlation between SM and antecedent Pr varies with soil depth and lag time. The antecedent Pr anomaly ( 1 or 2 months in advance) can be used to some extent as a surrogate SM anomaly in most regions except for in arid regions. This result is further demonstrated by the relationships between the SM anomaly and the standardized precipitation index. The current SM dataset can be used in various applications, such as validating satellite-retrieved products and model outputs.
\end{abstract}

\section{Introduction}

Soil moisture (SM) is an important land surface hydrology element. It interacts with the near-surface climate through land-atmosphere feedbacks and is also a linkage of atmosphere and the soil. SM is also one of the key variables influencing the nature eco-environment and agriculture. The role of SM on climate change and climate variability has been investigated in many studies (Sun et al. 2005; Yang et al. 2007; Shi 2009; Vivoni et al. 2009; Seneviratne et al. 2010; Koster et al. 2016; Orth and Seneviratne 2017). Orth and Seneviratne (2017) indicated that the SM has similar importance as sea surface temperatures for affecting the warm-season climate over the extrapolar regions. In agricultural practices, SM controls the plant growth and thus is usually treated as an indicator for agricultural drought (e.g.,

Corresponding author: Aihui Wang, wangaihui@mail.iap.ac.cn
Wang et al. 2009, 2011). Phase 6 of the Coupled Model Intercomparison Project (CMIP6) initialized a project, the Land Surface, Snow and Soil Moisture Model Intercomparsion Project (LS3MIP), in which SM is an important land surface element to be investigated (van den Hurk et al. 2016). All of the above (observed or model simulated) applications require a reliable and accurate SM database.

The classic SM measurement at a station is based on the gravimetric technique, in which wet soil samples are dug at different underground depths, and then the weights are compared before and after drying in an oven (S.U. et al. 2014). This process uses large amounts of manpower and is very inefficient, but it provides the most accurate SM measurements. In recent years, efforts have been made to improve SM measurements and to develop some state-of-art techniques, which would largely enhance the SM database. For instance, the cosmic-ray probe has been used to 
measure SM because the neutron transfer rate is sensitive to moisture in the soil (Zreda et al. 2012). More and more automated observation instruments have been installed and are used to continuously record SM in many regions. However, due to instrument malfunctions, change in environmental conditions, and other natural and manmade factors, the SM records from these modern techniques still contain uncerainties (e.g., S.U. et al. 2014; Wang et al. 2014). Apart from the ground-based measurements, SM can be retrieved from remote sensing products at relatively high resolution over continuous land regions, but they only characterize the soil moisture within a few centimeters of the surface (usually $0-5 \mathrm{~cm}$ ) and contain large biases over areas covered with dense vegetation and for areas with complex terrain (e.g., Zeng et al. 2015). The above deficiencies highly limit the applications of satellite-retrieved SM (Dorigo et al. 2015). Alternatively, SM simulated by climate models (including reanalysis products) is biased by the model physical processes and parameterization schemes, as well as by the computational errors (e.g., Wang et al. 2016). Thus, the SM records from the traditional gravimetric technique are the most reliable observations and are often treated as the "ground truth" to evaluate the datasets from other sources ( $\mathrm{Li}$ et al. 2005; Wang and Zeng 2011; Dorigo et al. 2015; Zeng et al. 2015; Wang et al. 2016). Compared to surface meteorology stations, the SM sites are usually very sparse and have poor spatiotemporal continuity, and these measurements also suffer from frequent interruptions. Nevertheless, the Global Soil Moisture Data Bank (Robock et al. 2000), which is now incorporated into the International Soil Moisture Network (https:// ismn.geo.tuwien.ac.at/networks/; Dorigo et al. 2011), has collected SM point measurements in different countries; however, some continents still have very few SM records.

China has the third-largest land area in the world and its climate and landscape show substantial spatial heterogeneity. The SM strongly depends on soil types, observation timing, and land cover, as well as on surface climate and environmental conditions; thus, it dramatically varies with space and time (S.U. et al. 2014; Feng et al. 2015). In the past two decades, SM point measurements at various numbers of Chinese stations have been analyzed and adopted in different applications (e.g., Zhang et al. 2004; Li et al. 2005; Nie et al. 2008; Yang et al. 2013; Feng et al. 2015). For instance, Li et al. (2005) used data from 40 Chinese stations from 1981 to 1991 to evaluate the three reanalysis products from ERA-40, NCEP-NCAR, and NCEP-DOE.
Nie et al. (2008) analyzed the SM spatiotemporal characteristics from 178 Chinese stations using data from 1981 to 1998. Although those stations have been used in the literature for data-model comparison, remote sensing validation, and other applications (e.g., $\mathrm{Li}$ et al. 2005; Ma et al. 2016), there are still too few to describe the spatial SM characteristics over all of China. Moreover, most of those datasets lack detailed measurement information, such as soil type and vegetation information. The raw SM measurements from the gravimetric technique are usually recorded as the relative wetness, which does not facilitate comparison with land surface model outputs (e.g., Wang and Zeng 2011; Wang et al. 2016) or to intercompare with other datasets such as reanalysis products, and satellite retrievals (e.g., Li et al. 2005; Ma et al. 2016). Furthermore, SM is usually measured at agrometeorological stations, which are greatly affected by irrigation in some regions (Nie et al. 2008). The above information is seldom stated in the literature. Therefore, it is necessary to derive a user-convenient SM observation database for various applications.

In addition, as one of key elements of land-atmosphere interaction, SM variations are affected by near surface atmospheric variables such as precipitation and air temperature, and in turn, the feedback of SM to the near-surface climate through indirectly regulating the latent heat fluxes via evapotranspiration and the sensible heat flux via partition of available radiation (Betts 2004; Dirmeyer 2011). The mechanisms of the above process rely on local climates associated with the time scales of interest (Betts 2004; Wang et al. 2006; Dirmeyer 2011). Increasing researches noticed that the spatial inconsistence between soil moisture and precipitation. For example, Feng and Zhang (2015) pointed out that global soil moisture varies with the climate zones. Over arid and semiarid regions, precipitation exerts the controlling role on the SM (Seneviratne et al. 2010; Wang and Zeng 2011).

The general sense is that the spatiotemporal variations in SM and precipitation ( $\mathrm{Pr}$ ) are consistent, since $\operatorname{Pr}$ is the only natural water source for soil. Due to the lack of long-term reliable in situ measured SM data over many regions of the world, much research uses the antecedent Pr or Pr-based moisture index as a proxy for SM, specifically, for moisture deficient conditions (e.g., Hirschi et al. 2011; Mueller and Seneviratne 2012; Meng and Shen 2014; Wang et al. 2015; Whan et al. 2015). For example, Meng and Shen (2014) used the standardized precipitation index to represent the SM deficiency, and they analyzed the relation between the proxy SM and extreme temperatures in eastern China. Holmes et al. (2017) used four Pr-based indices as SM 
surrogates to investigate the relationship between SM and the number of hot days in Australia. Nevertheless, few researchers extensively examine the rationality when the Pr-based moisture conditions are substituted for SM over large inhomogeneous climate regimes, such as China.

In this study, we collect the SM measurements (originally as relative wetness values) based on the gravimetric technique at more than 1000 stations on the Chinese mainland for 1991-2013. After carefully filtering the suspected low-quality data, we then obtain the SM records at 732 stations (with nearly complete records during growing seasons) in five soil layers. Using the additional soil characteristic parameters at each station for each soil layer, these SM data are then converted into the volumetric soil moisture (also referred to as SM, for short) for community use. Finally, we analyze those SM data in terms of their spatiotemporal and vertical characteristics, as well as the relationships with station-observed precipitation data. The purpose of this study is to provide a high-quality and userconvenient SM database as a benchmark for future applications, in particular, land-hydrology modeling validation, model assimilation, as well as the other applications. In addition, we have also tried to answer the question: does the antecedent precipitation accurately represent to SM for the different climate regimes of China?

\section{Data and methods}

\section{a. Soil moisture measurements}

The SM measurements at total of 1471 stations for the period from January 1992 to September 2013 were obtained from the National Meteorological Information Center (NMIC) of the Chinese Meteorological Administration (CMA; http://data.cma.cn/). The measurements were obtained on the 8 th, $18 \mathrm{th}$, and $28 \mathrm{th}$ of every month at five soil depths $(10,20,50,70$, and $100 \mathrm{~cm})$. These SM datasets were measured by the gravimetric thermal technique, in which a soil sample (usually between 100 and $200 \mathrm{~g}$ ) is weighed before $\left(W_{t}\right)$ and after drying $\left(W_{d}\right)$, and then the water content $\theta_{m}$ is computed $\left[\theta_{m}=\left(W_{t}-W_{d}\right) / W_{d}=W_{w} / W_{d}\right]$, where $W_{w}$ is the weight of water in the soil sample. To facilitate soil water monitoring for crop growth, the measurements were scaled and recorded as the relative soil water content $\left[R=100 \% \times\left(\theta_{m} / \mathrm{FC}\right)\right]$, where the soil field capacity (FC) represents the maximum soil water content that the soil can hold. The term $R$ represents the degree of soil water saturation, and the magnitude of $R$ varies from $0 \%$ (dry soil) to $99 \%$ (near saturation).
In winter, due to the harsh environmental conditions and frozen soil, few measurements are available. The data availability for the upper three layers is much higher than that for the deeper layers.

To obtain these relatively continuous SM records, we have performed a series of quality controls. We first checked the data availability and continuity at each station, and then choose those stations with available 10-cm depth SM measurements (i.e., at least one in three measurements is available in a month) for more than five growing seasons (April-September) during the period from 1992 to 2013 . The $10-\mathrm{cm}$ SM record was used as the criteria because it was the most active layer, and it is also used in other research studies (e.g., Wang and Zeng 2011). Usually, if measurements at a station are not available for the $10-\mathrm{cm}$ soil layer, then they are also missing for other deep layers. There are 732 stations remaining with data from the $10-\mathrm{cm}$ soil depth after the above quality control processes. The station distribution is relatively denser in eastern China than in other regions (Fig. 1). The following analyses are based on those 732 stations for five soil layers.

\section{b. Volumetric soil water content and soil hydrologic properties}

As mentioned previously, the SM outputs of a land surface-hydrology model are usually formatted as the volumetric soil water content $\theta_{v}\left(\mathrm{~cm}^{3} \mathrm{~cm}^{-3}\right)$, which is the ratio of water volume in the soil $V_{w}\left(\mathrm{~cm}^{3}\right)$ to the total soil volume $V_{t}\left(\mathrm{~cm}^{3}\right)$. To conveniently use SM measurements in various applications, it is necessary to convert $R$ to $\theta_{v}$.

According to the relationship between mass and volume law (Maidment 1993),

$$
q_{v}=V_{w} / V_{t}=\left(W_{w} / W_{d}\right)\left(\mathrm{BD} / r_{w}\right)=R \times \mathrm{BD} \times \mathrm{FC} / r_{w},
$$

where $\mathrm{BD}\left(\mathrm{g} \mathrm{cm}^{-3}\right)$ denotes the soil bulk density and $\rho_{w}\left(\mathrm{~g} \mathrm{~cm}^{-3}\right)$ is the density of water, usually assumed to be $1 \mathrm{~g} \mathrm{~cm}^{-3}$. The BD is the mass of soil divided by the total volume of soil including solids and pores, which is extracted at each station location from a high-resolution soil properties database in China (Shangguan et al. 2014). Figures $2 \mathrm{a}-\mathrm{c}$ show the spatial distributions of BD at 10,20 , and $100 \mathrm{~cm}$ for the 732 stations in China, respectively. The BD magnitude varies between 1.0 and $1.6 \mathrm{~g} \mathrm{~cm}^{-3}$, and the mean BD increases with the soil depth with values of $1.28 \pm 0.08$ (standard deviation), $1.35 \pm 0.07$, and $1.39 \pm 0.07 \mathrm{~g} \mathrm{~cm}^{-3}$ from upper to deep layers, respectively.

The FC is the maximum soil water content before soil water drainage due to gravity force. For specific soil 


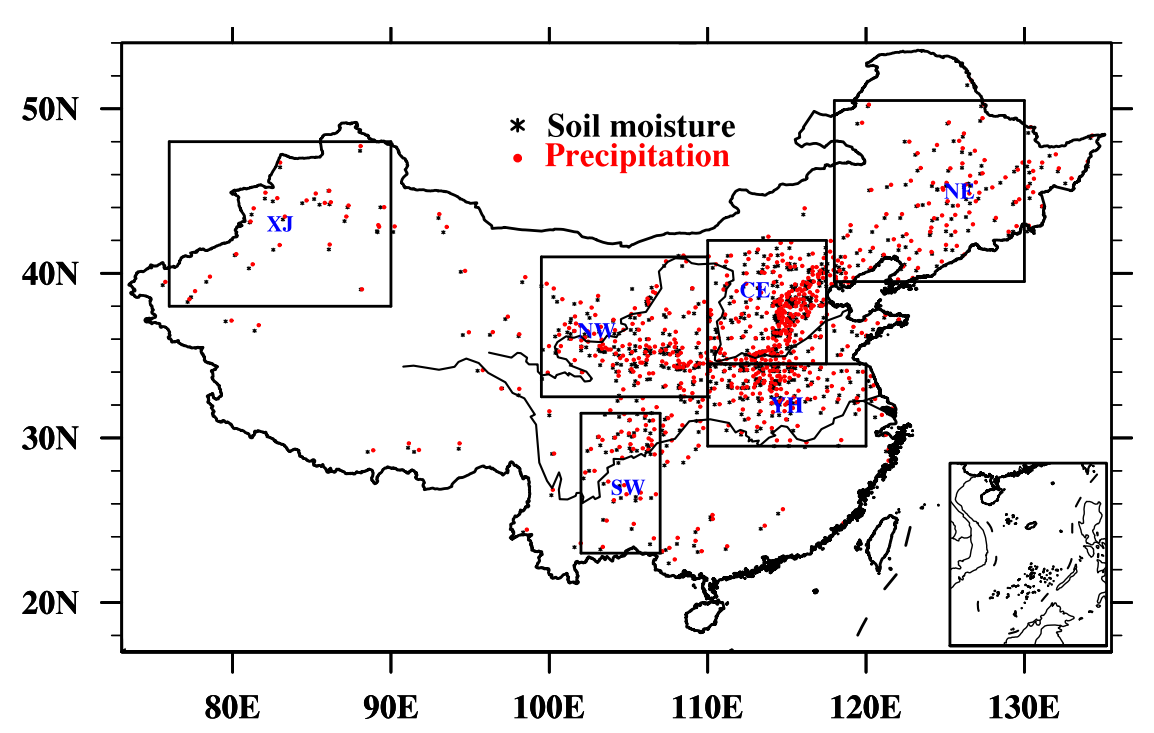

FIG. 1. Locations of soil moisture (black stars) and precipitation (red dots) at 732 stations in China. The boxes indicate the regional range with the two-letter abbreviations provided for each region $\left(\mathrm{XJ}: 76^{\circ}-90^{\circ} \mathrm{E}, 38^{\circ}-48^{\circ} \mathrm{N}\right.$; NW: $99.5^{\circ}-110^{\circ} \mathrm{E}, 32.5^{\circ}-41^{\circ} \mathrm{N}, \mathrm{CE}: 110^{\circ}-117.5^{\circ} \mathrm{E}, 34.5^{\circ}-$ $42^{\circ} \mathrm{N}, \mathrm{NE}: 118^{\circ}-130^{\circ} \mathrm{E}, 39.5^{\circ}-50.5^{\circ} \mathrm{N}$; YH: $110^{\circ}-120^{\circ} \mathrm{E} 29.5^{\circ}-34.5^{\circ} \mathrm{N}$, and $\mathrm{SW}: 102^{\circ}-107^{\circ} \mathrm{E}, 23^{\circ}-$ $\left.31.5^{\circ} \mathrm{N}\right)$.

types and soil depths, the magnitude of the soil water sucking pressure (soil matric potential, zero at the surface and positive upward) decreases with the soil water content, and laboratory experiments based on limited soil samples indicated that the FC is approximately equal to the soil water content at the $-33 \mathrm{~J} \mathrm{~kg}^{-1}$ sucking pressure (Maidment 1993). Because the FC at stations is not easily measured, lookup tables based on the soil texture classes were often used in practice (Maidment 1993). However, the soil properties in the lookup tables were usually derived from a few soil samples (e.g., Cosby et al. 1984), which might not reflect the spatial heterogeneity of soils. In numerical models, FC was usually computed from the empirical pedotransfer functions (PTFs) based on other soil parameters from soil surveys (Clapp and Hornberger 1978). Dai et al. (2013) has developed the FC datasets using the 10 existing PTFs based on the best available soil characteristics dataset in China (Shangguan et al. 2014) and found that the FCs from different PTFs were quite similar, and over most areas, the coefficients of variation from 10 PTFs were less than 0.15 . Since this cannot be validated, the median FCs from 10 PTFs are used in Eq. (1). Figures $2 b-d$ plot the FC at 10,20 , and $100 \mathrm{~cm}$ at the 732 stations in China, respectively. The magnitude of $\mathrm{FC}$ varies between 0.15 and $0.41 \mathrm{~cm}^{3} \mathrm{~cm}^{-3}$ with the relatively large values appearing in eastern China between the Yangtze and Yellow River basins and the relatively small magnitudes are in northern China. For all 732 stations, the mean FCs and the standard deviation of FC are approximately 0.27 and 0.05 for all three soil layers, respectively.

\section{c. Precipitation measurements}

In this study, the daily precipitation measurements at more than 2400 stations are also obtained from the NMIC (http://data.cma.cn/). Precipitation is routinely observed at the meteorological stations with relatively dense distribution, while SM is measured at the agricultural sites. At each SM station, the closest meteorological station was retrieved and indicated in Fig. 1. We can clearly see that the locations of the SM and Pr stations are not exactly same. Over 732 stations, the distances between our selected Pr stations and SM stations vary between 0 and $131 \mathrm{~km}$ with a median (mean) distance of $31 \mathrm{~km}(30 \mathrm{~km})$, and more than $80 \%$ of the station pairs are less than $40 \mathrm{~km}$ apart. This distance is within the spatial representativeness (SR) of point measured SM (e.g., Famiglietti et al. 2008; Nie et al. 2008; Nicolai-Shaw et al. 2015). For instance, Nie et al. (2008) calculated the SR based on a spatial autocorrelation method in terms of SM measurements during 1987-98 at the 178 Chinese stations and reported that the spatial scale of SM in China was $200 \sim 600 \mathrm{~km}$ for the long time mean. Nicolai-Shaw et al. (2015) used a "spatial footprint" method to investigate the SR of SM in point measurements, remote sensing, and reanalysis in the United States, and indicated the SR of SM was approximately a few hundred kilometers. The SR 

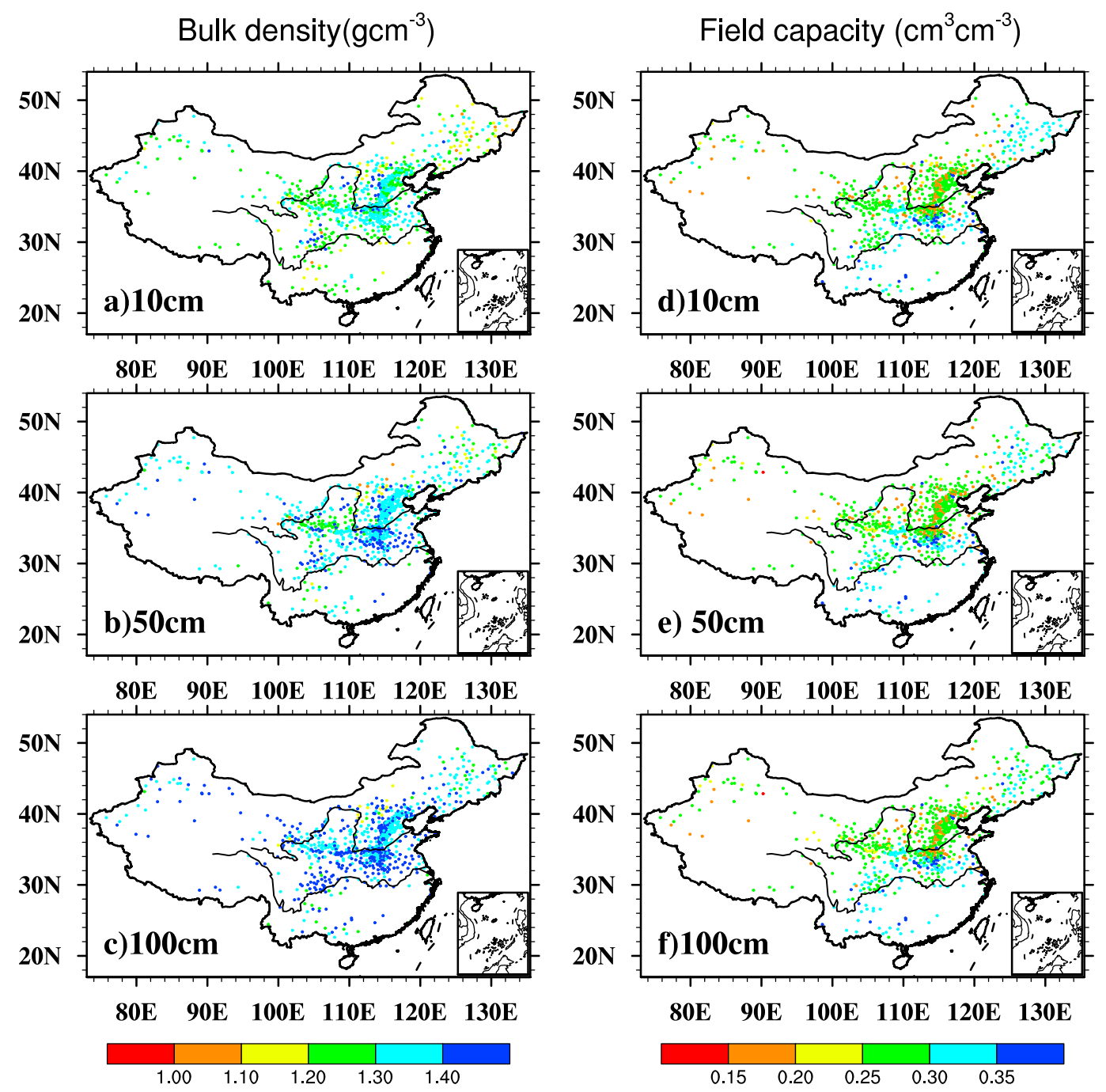

FIG. 2. (a),(c) Soil bulk density and (b),(d) soil field capacity at 732 stations for the 10-, 50-, and 100-cm soil layers retrieved from Shangguan et al. (2013) and Dai et al. (2013), respectively.

of SM also depends on the temporal scale of interest. If we study hourly SM over heterogeneous land surface, variabilities of SM within small area need to be considered. It should be noted that some studies used interpolation algorithms (e.g., bilinear interpolation) to interpolate Pr to the locations of SM. We prefer to use the closest distance method to avoid the artificial errors introduced by the interpolation method. To facilitate illustration, the locations of the selected Pr are treated at the same stations as the SMs in the following analyses and plots.

\section{d. Methodology}

Based on Eq. (1) and the soil hydrological properties shown in Fig. 2, we converted the raw SM records at each station from the relative soil wetness $R$ to the volumetric soil water content $\theta_{v}$. To make the data more useful and reliable, we then computed the monthly mean $\theta_{v}$ using all available records at each station. If all three records are missing within a month at a station, the monthly $\theta_{v}$ is then assigned the missing value. To analyze the SM variations over large areas, we divided the majority SM stations into six subregions: northeast (NE, 81 stations), central east (CE, 213 stations), northwest (NW, 135 stations), Xinjiang (XJ, 34 stations), Yangtze-Huaihe River basin (YH, 134 stations), and southwest (SW, 40 stations). The range of each subregion is also indicated in Fig. 1. The divisions of those subregions are based on the station distribution, data availability, and climate conditions, and we also referred to previous studies (Nie et al. 2008; Ma et al. 2016). The arithmetic average SM at all stations in each subregion then represents the regional mean magnitude. In the following sections, the spatial and temporal 

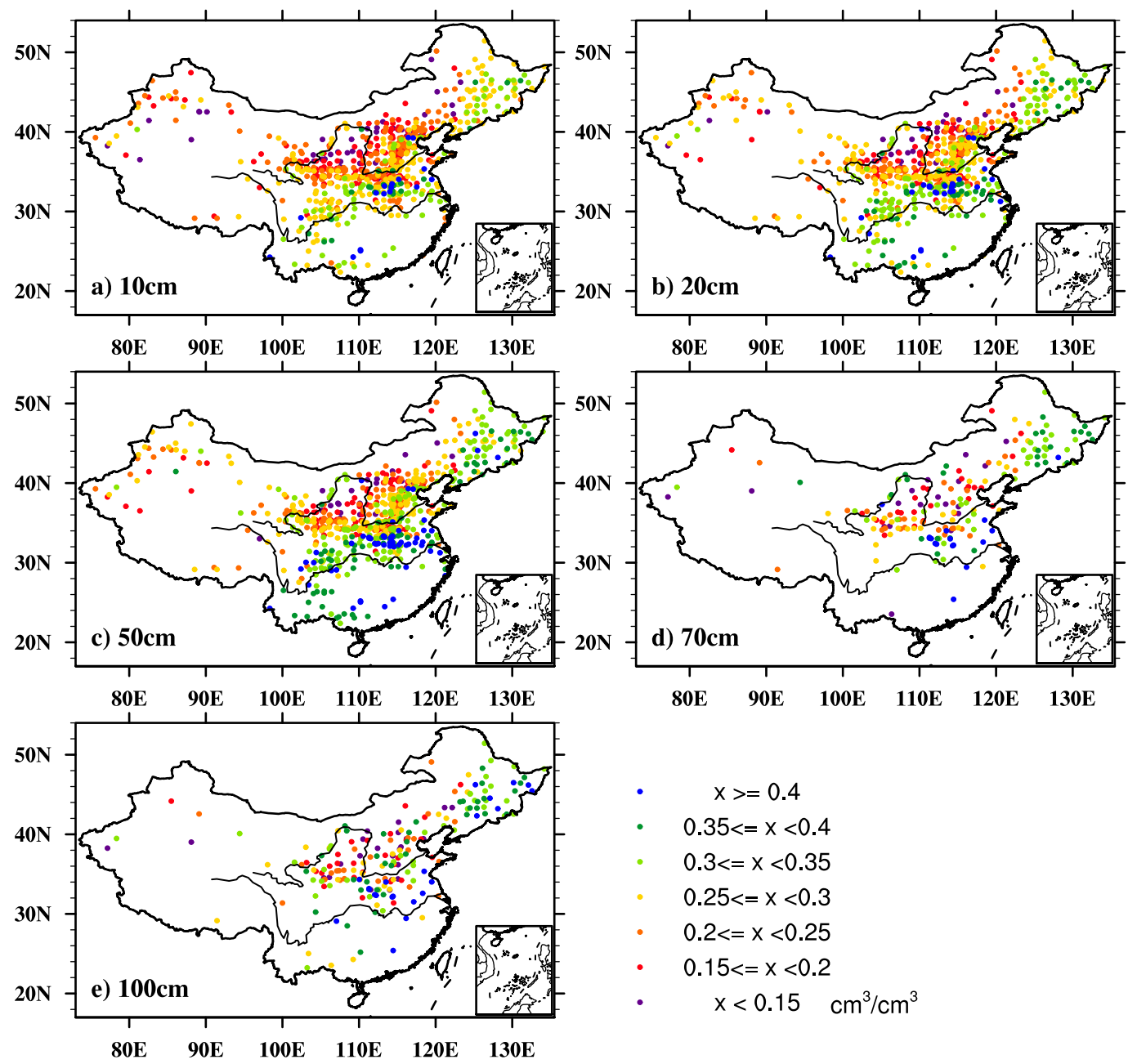

FIG. 3. The mean volumetric soil water content $\theta_{v}\left(\mathrm{~cm}^{3} \mathrm{~cm}^{-3}\right)$ averaged over the growing season (AprilSeptember) from 1992 to 2013.The number of stations for soil depths of (a) $10 \mathrm{~cm}$ (732 stations), (b) $20 \mathrm{~cm}$ (732 stations), for (c) $50 \mathrm{~cm}$ (730 stations), (d) $70 \mathrm{~cm}$ (183 stations), and (e) $100 \mathrm{~cm}$ (203 stations).

characteristics, as well as the vertical profile of monthly $\theta_{v}$ at each station and in each subregion will be extensively analyzed. The autocorrelation coefficient of SM time series is used to represent the SM memory, and the least squares method is adopted to compute the SM linear trend. Additionally, the relationship between Pr and SM and between the standardized precipitation index and SM in different layers and for different subregions are also addressed and discussed.

\section{Spatial and temporal characteristics of soil moisture in China}

\section{a. Spatial distribution of climatology mean soil moisture}

In consideration of the data availability, there are few missing records during the growing season (April-
September). Thus, to investigate the spatial variations of SM, we first computed the mean $\theta_{v}$ at each station in each growing season and then the multiple growing seasonal mean from 1992 to 2013 (Fig. 3). The mean $\theta_{v}$ shows apparent spatial variability over the $\mathrm{NE}, \mathrm{YH}$, and SW subregions, but displays small variability over the NW, CE, and XJ subregions (Table 1). In general, the magnitude of $\theta_{v}$ increases from north to south, and from west to east, which is similar to the Pr distribution (figure not shown). Specifically, stations with relatively wet soil $\left(\theta_{v} \geq 0.4 \mathrm{~cm}^{3} \mathrm{~cm}^{-3}\right)$ are mainly located in areas from the middle to lower reaches between the Yangtze and Yellow River basins. From the upper to deep soil layers, the $\theta_{v}$ varies from station to station. The mean $\theta_{v}$ from all available stations (732 stations at $10-$ and $20-\mathrm{cm}$ depths, 730 stations at $50-\mathrm{cm}$ depth, 183 stations at $70-\mathrm{cm}$ depth, and 203 stations at $100-\mathrm{cm}$ depth) are 0.24 , 
TABLE 1. Regional mean soil moisture $\left(\mathrm{cm}^{3} \mathrm{~cm}^{-3}\right)$ averaged over the growing season (April-September) for different soil layers from 1992 to 2013. The values in parentheses are the corresponding interannual coefficients of variation $(\mathrm{CV} ; \%)$. The $\mathrm{CV}$ is computed as the ratio of the mean to the interannual standard deviation.

\begin{tabular}{lccccc}
\hline \hline & $10 \mathrm{~cm}$ & $20 \mathrm{~cm}$ & $50 \mathrm{~cm}$ & $70 \mathrm{~cm}$ & $100 \mathrm{~cm}$ \\
\hline XJ & $0.20(6.06)$ & $0.23(3.75)$ & $0.25(3.69)$ & - & - \\
NW & $0.22(3.69)$ & $0.24(3.14)$ & $0.24(3.89)$ & $0.22(9.09)$ & $0.23(9.66)$ \\
CE & $0.21(5.73)$ & $0.22(5.15)$ & $0.24(3.92)$ & $0.24(6.86)$ & $0.25(6.67)$ \\
NE & $0.26(5.53)$ & $0.28(4.99)$ & $0.30(4.64)$ & $0.31(5.69)$ & $0.31(6.81)$ \\
SW & $0.30(4.46)$ & $0.32(3.50)$ & $0.35(2.76)$ & - & - \\
YH & $0.28(6.48)$ & $0.30(5.36)$ & $0.33(4.58)$ & $0.37(8.27)$ & $0.37(8.12)$ \\
\hline
\end{tabular}

$0.26,0.28,0.276$, and 0.28 , respectively, indicating the nonlinear change in SM with depth.

\section{b. Seasonal and interannual variations in soil moisture}

Figure 4 shows the mean seasonal cycle of $\theta_{v}$ over each subregion for the period from 1992 to 2013. Note that because of too much missing data at $70-$ and $100-\mathrm{cm}$ depths over XJ and SW, the mean monthly (Fig. 4) and annual mean $\theta_{v}$ (Fig. 5) are only computed for the top three layers. In China, the climate is strongly affected by the East Asian monsoon, thus Pr shows clear seasonality with the largest amount occurring in summer and being smallest in winter (Fig. 4). Over each subregion, the $\theta_{v}$ does show a certain seasonality, but its seasonal variability is not as distinct as that of Pr. Furthermore, the seasonal variability $\theta_{v}$ changes with regions. For example, over the arid region $\mathrm{XJ}$, the maximum $\mathrm{Pr}$ appears in July with a value of $0.92 \mathrm{~mm} \mathrm{day}^{-1}$, whereas the soil is relatively wet in February $\left(0.27 \mathrm{~cm}^{3} \mathrm{~cm}^{-3}\right)$, and then turns dry until August $\left(0.17 \mathrm{~cm}^{3} \mathrm{~cm}^{-3}\right)$. Over humid region SW, the maximum $\mathrm{Pr}$ in July is $5.62 \mathrm{~mm}$ day $^{-1}$, and the $\theta_{v}$ is smallest in both February and March $\left(0.27 \mathrm{~cm}^{3} \mathrm{~cm}^{-3}\right)$ and then increases until the largest magnitude appears in September $\left(0.31 \mathrm{~cm}^{3} \mathrm{~cm}^{-3}\right)$.

Table 1 summarizes the multigrowing season mean of $\theta_{v}$ over six subregions during the study period. It clearly shows that the deep soil is generally wetter than the shallow layers. For instance, the regional mean $\theta_{v}$ in the SW increases from $0.30 \mathrm{~cm}^{3} \mathrm{~cm}^{-3}$ at $10 \mathrm{~cm}$ to $0.37 \mathrm{~cm}^{3} \mathrm{~cm}^{-3}$ at $100-\mathrm{cm}$ depth. This feature can be explained as the upper soil layers are more easily affected by atmospheric processes, such as solar radiation and wind. Therefore, the moisture cannot be held for a longer time in the shallow soil layers. The soil water in the deep soil layers is less affected by atmospheric processes, and it usually maintains a certain level for supporting vegetation growth. Figure 5 also shows the apparently interannual variability of SM, which displays similar variability as $\operatorname{Pr}$ (figure not shown), implying that $\mathrm{Pr}$ is the main driver of SM variation at annual scale. To quantify the interannual variability of $\mathrm{SM}$, the coefficient of variation $(\mathrm{CV})$, defined as the ratio of the standard deviation (STD) to the annual mean $\theta_{v}$, is computed for each layer for each region (Table 1). Because the climatology mean of SM are regionally heterogeneous, we use the CV to represent the relative variability, which facilitates intercomparison across subregions and soil depths. The magnitude of $\mathrm{CV}$ varies from $2.76 \%$ (at $50 \mathrm{~cm}$ in $\mathrm{SW}$ ) to $9.66 \%$ (at $100 \mathrm{~cm}$ in NW). Over each subregion, the $\mathrm{CV}$ is generally larger in the deep layers (i.e., 70, $100 \mathrm{~cm}$ ) than in the shallow layers (i.e., $10,20,50 \mathrm{~cm}$ ). Famiglietti et al. (2008) indicated that the SM spatial variability generally increased with the scale extent. Here, our analyses show the SM variability at annual scale is prominent in the deeper soil layers. In additional to climatic variables, SM is also affected by local factors. For example, the vegetation canopy can intercept rainfall and reduce water arriving at the soil surface; meanwhile, the vegetation shading effect also decreases the solar radiation drying soil surface. These processes involve complicated atmosphere-land-soil interactions (Seneviratne et al. 2010).

\section{c. Linear trends of soil moisture}

To further investigate the temporal variation of SM over each station, we computed the linear trend of the growing season mean SM during the study period by using the least squares method. Because the measurements at 70 - and $100-\mathrm{cm}$ depths contain too many missing records, we only plotted stations with trends passing a significance test $(p=0.05)$ for the upper three layers (Fig. 6). At the majority of stations with available SM data for different soil layers, the trends in the regional mean SM do not pass the significance test $(p=0.05$, figure not shown). The mean and STD of trends across stations in Fig. 6 are $9.35 \times 10^{-7} \pm 6.91 \times$ $10^{-4}, 7.37 \times 10^{-3} \pm 8.30 \times 10^{-3}$, and $2.45 \times 10^{-3} \pm$ $2.06 \times 10^{-3} \mathrm{~cm}^{3} \mathrm{~cm}^{-3} \mathrm{yr}^{-1}$ at $10-, 20-$, and $50-\mathrm{cm}$ soil depths, respectively. The positive mean trends indicate the overall wetting tendency of soil during the study period, while the STDs of trends in different layers denote the spatial heterogeneity in the SM vertical profile. Moreover, the number of stations with significant uptrends is greater than those with significant downtrends in all three layers, and in the deeper layers, the number of stations with significant trends slightly increases. For instance, at $10-\mathrm{cm}$ depth there are 122 stations with significant uptrends, but 99 stations have significant downtrends; however, at 20- and 50-cm depths, the number of stations with significantly positive (negative) SM trends is 132 (94) and 135 (111), respectively. Among all stations, 

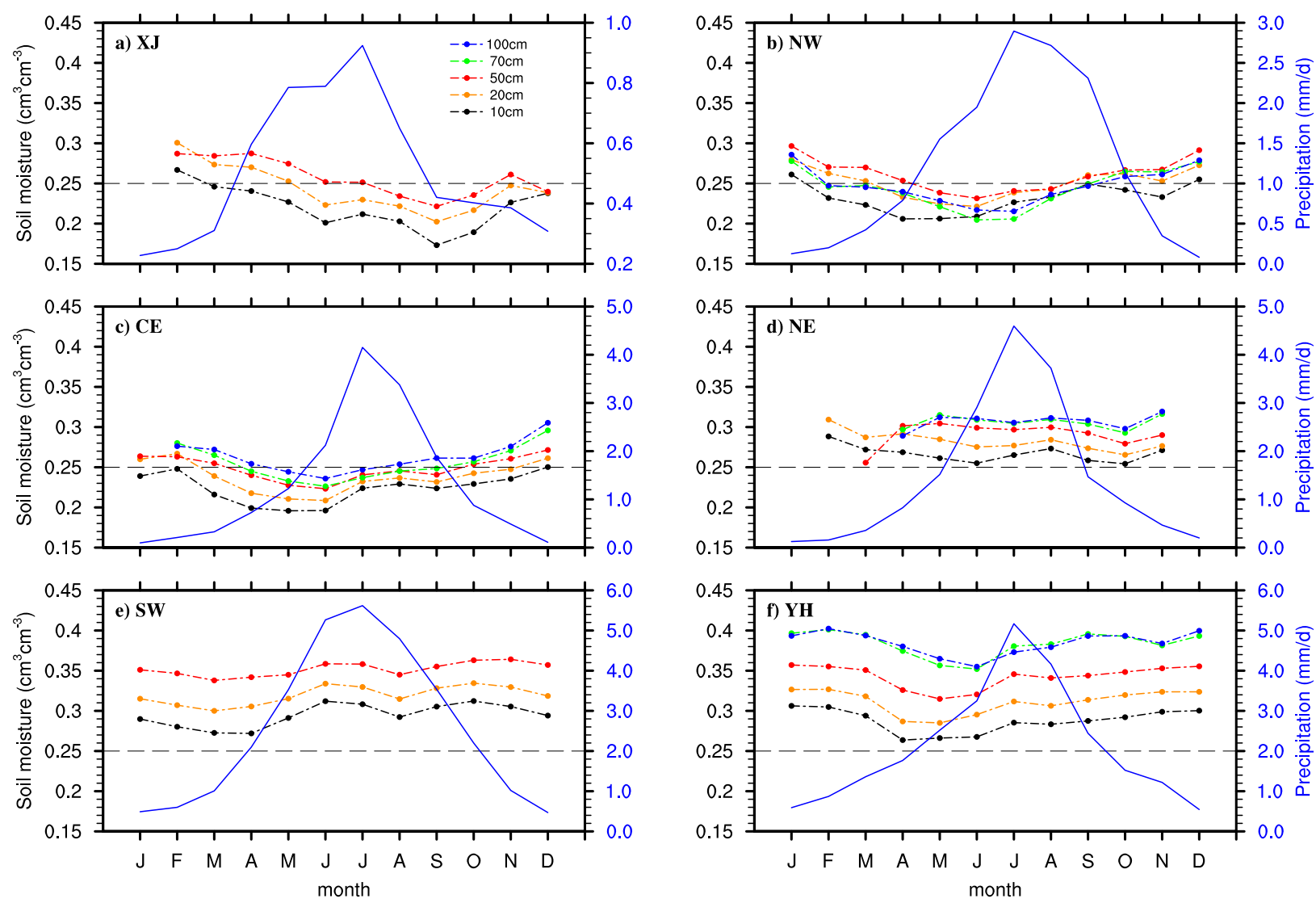

FIG. 4. Mean seasonal cycles of volumetric soil moisture for five layers (left $y$ axis, dashed curve) and precipitation (right $y$ axis, blue solid curve) averaged over different regions for the period from 1992 to 2013.

the linear trends show large spatial variations and vertical variations. The stations with larger SM uptrends are located near the Jing-Jin-Ji (Beijing, Tianjin, and Hebei provinces) area of the $\mathrm{CE}$ subregion in all three layers and central east China at 50-cm depth, where the trend magnitudes of some stations are greater than $0.012 \mathrm{~cm}^{3} \mathrm{~cm}^{-3} \mathrm{yr}^{-1}$. The distinct SM trends (positive or negative) appear in the areas between the middle and lower reaches of the Yangtze and Yellow River basins. Over other regions, SM trends are not coherent in different soil layers. Moreover, to further investigate the temporal SM trends over different soil layers, we count the number of stations with the same trend sigh in all three layers. We find that there are only 264 stations with trend sign consistence in all three layers, but there are 464 stations with that inconsistent sign of trends (note that the stations with available data are not necessarily the same for different layers). This result implies a nonlinear change of SM for the longterm in the vertical direction.

\section{d. Soil moisture memory}

The SM could store current land and climate information and dissipate later to influence the future weather and climate. This SM characteristic is usually called "SM memory," and it has wide implications for numerical weather predictions (Koster and Suarez 2001; Orth and Seneviratne 2017). For instance, the sensitivity experiments based on both the simple model and AGCM indicated that local SM anomalies can impact both local atmospheric circulation and remote climate in the boreal summer in North America (Koster et al. 2016). Soil moisture autocorrelation (Auto-Corr) is usually used to describe the soil moisture memory (e.g., Koster and Suarez 2001; Wu and Dickinson 2004; Wang et al. 2006). To take insight from the above SM temporal variations, we computed the Auto-Corr using $\theta_{v}$ at 10,20 , and $50 \mathrm{~cm}$ with a 1-3-month lag for each subregion (Fig. 7). It clearly shows that the Auto-Corr decreases with an increase in lag time. For all three soil layers, the magnitude of Auto-Corr is greater than 0.5 at lag for 1 month, but it is below 0.1 at lag for 3 months over most subregions. When comparing the Auto-Corrs at different layers, we find that the magnitudes for both the 1-month-lag and the 2-month-lag Auto-Corr for the 50-cm soil layer are larger than those for other two layers at five subregions, 

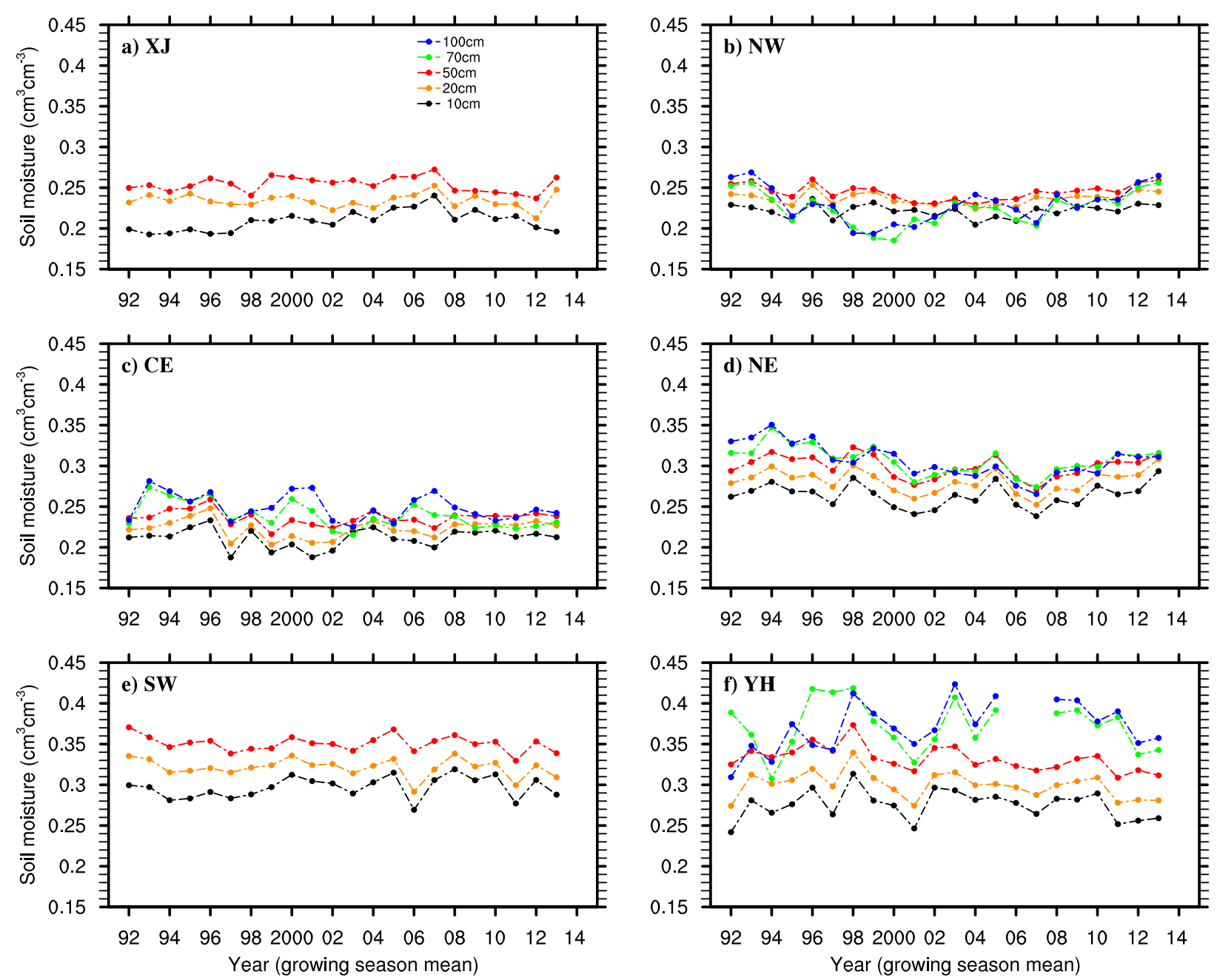

FIG. 5. Time series of annual volumetric soil moisture in five layers averaged over different regions from 1992 to 2013 . Similar to Fig. 4, the annual value denotes the mean from April to September in each year.

excluding NE and XJ. This implies that the SM retention in the deep layers is longer than in the shallow layers; that is, the SM memory increases with soil depth, which also has been reported in previous studies (e.g., Koster and Suarez 2001; Wu and Dickinson 2004; Wang et al. 2006). There is an exception in the NE region where SM memory is longer than that in other subregions at a specific time lag, and the 3-month-lag Auto-Corr is greater than $0.3(p=0.05)$ at the 10 - and $20-\mathrm{cm}$ depths. The NE is a major irrigation-fed agricultural area in China, where irrigation regularly replenishes water in the soil and the SM remains at a certain level for crop growing. Thus, the SM retention in NE is much longer than for other regions. Ma et al. (2016) analyzed SM datasets in China from in situ measurements, land surface model outputs, and satellite measurements, and they concluded that irrigation greatly affected the SM long-term trend. Irrigation is one of the major anthropogenic interferences on the soil, and it alters the natural water input to the soil. However, current land surface components in the GCMs do not always involve the irrigation process, but the in situ measured SM is inevitably affected by irrigation over those areas. This usually causes an inconsistency between model and data, which deserves to be investigated in detail.

\section{e. Drought and flood based on SM records: Case study}

The SM deficiency is often used as an indicator of agricultural drought (Wang et al. 2009, 2011) because it reflects the dryness in the soil and controls plant growth over vegetated regions. Conversely, a positive SM anomaly with respect to climatology can also reflect flooding. In China, $\mathrm{CE}$ and $\mathrm{YH}$ are two regions with dense populations and they frequently suffer from the 


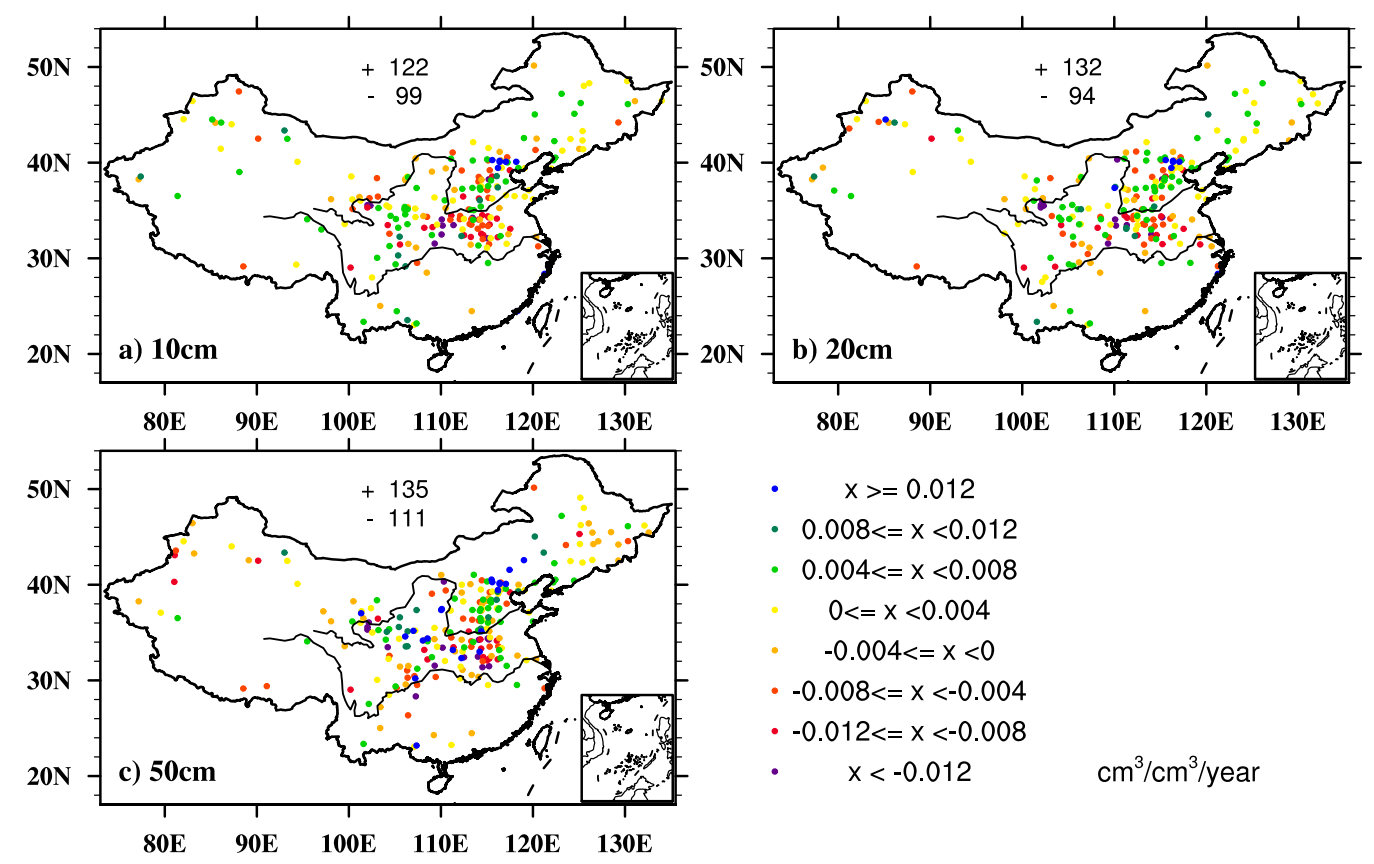

FIG. 6. The linear trend of annual volumetric soil moisture at each station from 1992 to 2003 for the (a) 10-, (b) 20-, and (c) 50-cm soil layers. The annual value is the mean from April to September in each year. Only stations with trends passing a significance test $(p=0.05)$ are shown. The values with " $+/-$ " in each figure indicates the number of stations with significant uptrends/downtrends.

meteorological hazards, such as droughts, floods, and heat waves (Liu and Zhang 2002; Wang et al. 2011). As an illustration of SM applied to the drought and flood investigations, we plotted SM anomalies (10-cm level) over both $\mathrm{CE}$ and $\mathrm{YH}$, and the corresponding regional average Pr anomaly for the growing season from 1992 to 2013 (Fig. 8). Over CE, it frequently appears the large magnitudes of SM anomaly. If we use a $\pm 0.03 \mathrm{~cm}^{3} \mathrm{~cm}^{-3}$ SM anomaly and a $\pm 1.0 \mathrm{~mm} \mathrm{day}^{-1} \operatorname{Pr}$ anomaly as the thresholds, we find that severely dry soil appeared in 1995, 1997, 1999, 2001, 2003, 2007, and 2013, and severely wet soil was present in 1994, 1996, 1998, 2005, 2006, and in early 2013. Correspondingly, the Pr anomalies also show large negative (positive) values during dry (wet) SM years. For instance, northern China suffered a severe drought in the summer 1997, and it caused that the Yellow River to dry up for 226 days from the middle to lower reaches (Liu and Zhang 2002). Figures $8 \mathrm{a}$ and $8 \mathrm{~b}$ clearly show the distinct negative SM anomalies (up to $-0.05 \mathrm{~cm}^{3} \mathrm{~cm}^{-3}$ at $10-\mathrm{cm}$ soil depth in August 1997) and Pr anomalies (-1.24, -1.56, and $-1.84 \mathrm{~mm} \mathrm{day}^{-1}$ in June, July, and August 1997, respectively). Actually, this drought event extended to more regions after 2000 (e.g., Wang et al. 2011). Because the climate in $\mathrm{YH}$ is dominantly affected by both the East Asia summer monsoon system and the subtropical high system, both climatology mean Pr and SM over
YH were all much larger than that in CE (cf. Figs. 5 and 6). Moreover, the interannual variability of climate elements in the $\mathrm{YH}$ region is also relatively large (e.g., Fig. 6f, Table 1). Similar to CE, we also established threshold lines for both the SM anomaly $\left( \pm 0.04 \mathrm{~cm}^{3} \mathrm{~cm}^{-3}\right)$ and the Pr anomaly $\left( \pm 2.0 \mathrm{~mm} \mathrm{day}^{-1}\right)$ in YH (Figs. 8c,d). It can be seen that apparently negative/positive SM and Pr anomalies occurred frequently and coherently during the study period. Specifically, the catastrophic 1998 flood in the Yangtze River basin caused serious damage and great economic losses (Zong and Chen 2000). In May 1998, the Pr shows large positively abnormal $\left(3.4 \mathrm{~mm} \mathrm{day}^{-1}\right)$, while the corresponding SM anomalies for both $10-$ and $20-\mathrm{cm}$ soil layers are also greater than $0.07 \mathrm{~cm}^{3} \mathrm{~cm}^{-3}$. Other distinct flood and drought events are also indicated by both the SM and Pr anomalies. Because Pr represents the moisture from the atmosphere, SM denotes the moisture from the soil, and both can be used to indicate the moisture conditions of the land. They show similar temporal variability and the concurrent correlation is 0.60 for $\mathrm{CE}$ and 0.65 for $\mathrm{YH}$ (cf. Fig. 9), but they have a nonlinear relationship due to various impact factors, such as evaporation, soil texture, and vegetation types. From Fig. 8, we can also find that in some years, SM might show substantial anomalies, but the Pr anomalies do not show coherent behavior. For instance, at YZ in 2007, 

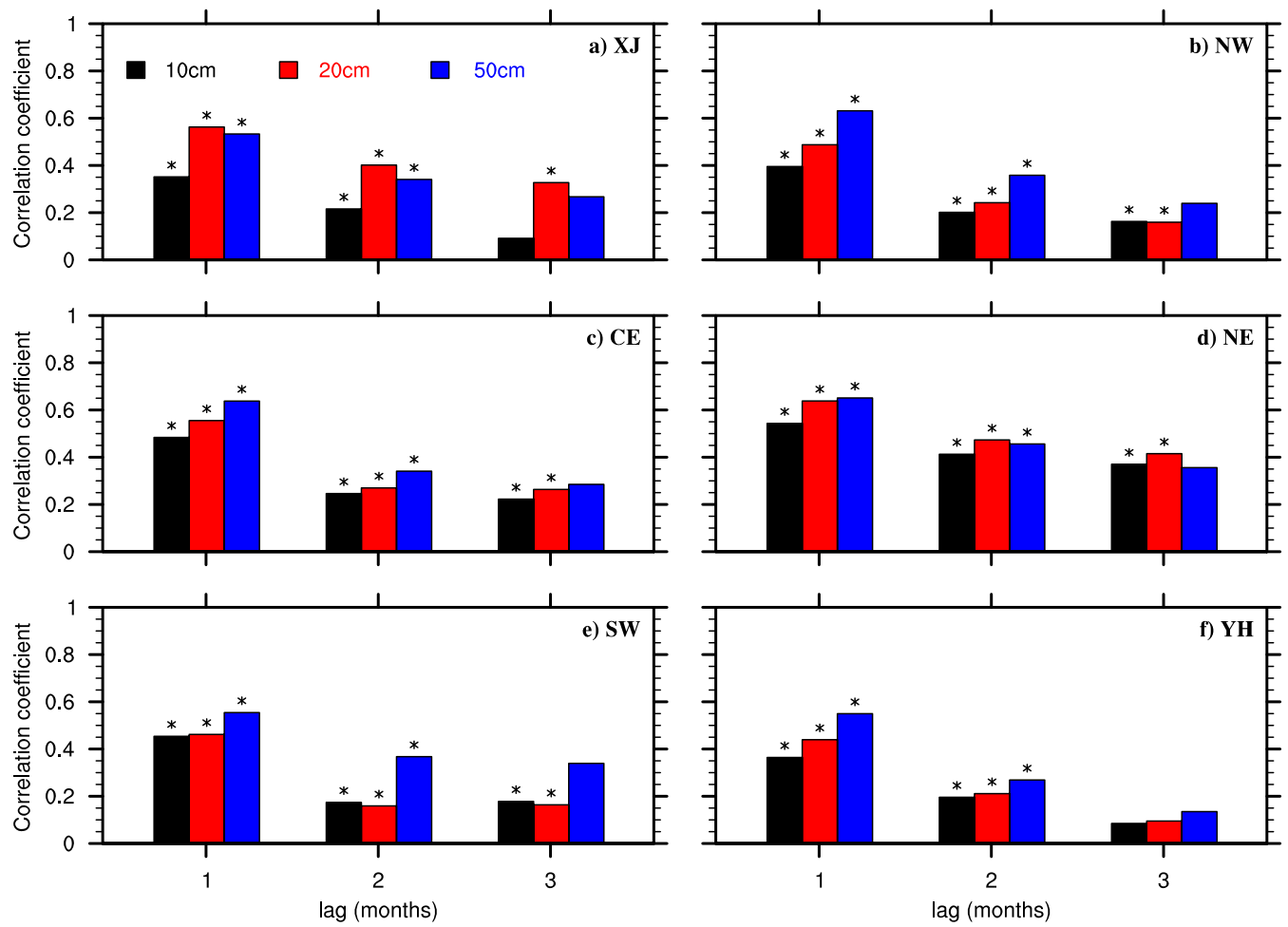

FIG. 7. Bar plots of the autocorrelations of soil moisture at lags of 1, 2, and 3 months over six subregions. The bars with stars above indicate that correlation is significant at the $95 \%$ confidence level.

Pr shows a distinct positive anomaly and the July $\mathrm{Pr}$ anomaly is $3.42 \mathrm{~mm} \mathrm{day}^{-1}$, but the SM anomalies from July to September are smaller than $0.03 \mathrm{~cm}^{3} \mathrm{~cm}^{-3}$. Moreover, the SM anomaly in May is near $-0.08 \mathrm{~cm}^{3} \mathrm{~cm}^{-3}$, while the $\mathrm{Pr}$ anomaly is only $-0.54 \mathrm{~mm} \mathrm{day}^{-1}$ in May and $-0.73 \mathrm{~mm} \mathrm{day}^{-1}$ in April. The above results indicate that the SM-based agricultural drought does not always happen along with the meteorological drought. This issue will be further addressed in section 4 .

On the other hand, from the simplified land surface water balance equation: $\Delta \mathrm{SM}=\operatorname{Pr}-E-R$, changes in water in the soil $(\Delta \mathrm{SM})$ are affected by the water source term $(\operatorname{Pr})$, and by the water sink terms (evaporation $E$ and runoff $R$ ). Therefore, when we discuss the relationship between $\mathrm{Pr}$ and SM in the future, other surface hydrology elements (e.g., $E$ and $R$ ) should be taken into consideration. On the other hand, the inconsistency between Pr and SM changes are also related to the moisture retention time of the soil (section $3 \mathrm{~d}$ ), which will be further addressed in the next section.

\section{Relationship between soil moisture and antecedent precipitation}

As we previously mentioned, the antecedent $\mathrm{Pr}$ or $\mathrm{Pr}$ index is often used as a surrogate for SM (Hirschi et al.
2011; Meng and Shen 2014; Whan et al. 2015; Holmes et al. 2017) due to the absence of long-term reliable SM datasets over many regions around the world. However, few studies have addressed the reliability of this substitution. In this section, we discuss this issue through analysis of the simple lag-time correlation coefficient between antecedent Pr and SM.

Over six subregions, Fig. 9 shows the cross correlation (Cross-Corr) between $\operatorname{Pr}$ and $\theta_{v}$ at 10-, 20-, and 50 -cm depth for $0,1,2$, and 3 months of lag. Over five subregions except for XJ, the concurrent Cross-Corrs (lag $=0$ month) are larger than 0.5 at both 10 - and $20-\mathrm{cm}$ soil depths, and they reduce slightly at $50-\mathrm{cm}$ depth. NE has the largest concurrent Cross-Corr with the $0.68,0.62$, and $0.50(p=0.05)$ at 10,20 , and $50 \mathrm{~cm}$, respectively. Similarly, Cross-Corrs for both 1- and 2 -month lags are significantly positive in the other five subregions, although their magnitudes decrease slightly with increases in lag time for the upper two soil layers. At the 50-cm soil layer, the 1-month-lag CrossCorrs are the largest among the three soil layers in four of six subregions except for XJ and SW. The significantly positive Cross-Corr between Pr and SM anomalies indicates that the antecedent Pr information can remain in soil for a while and that it can somehow represent the SM anomaly in nonarid regions. 

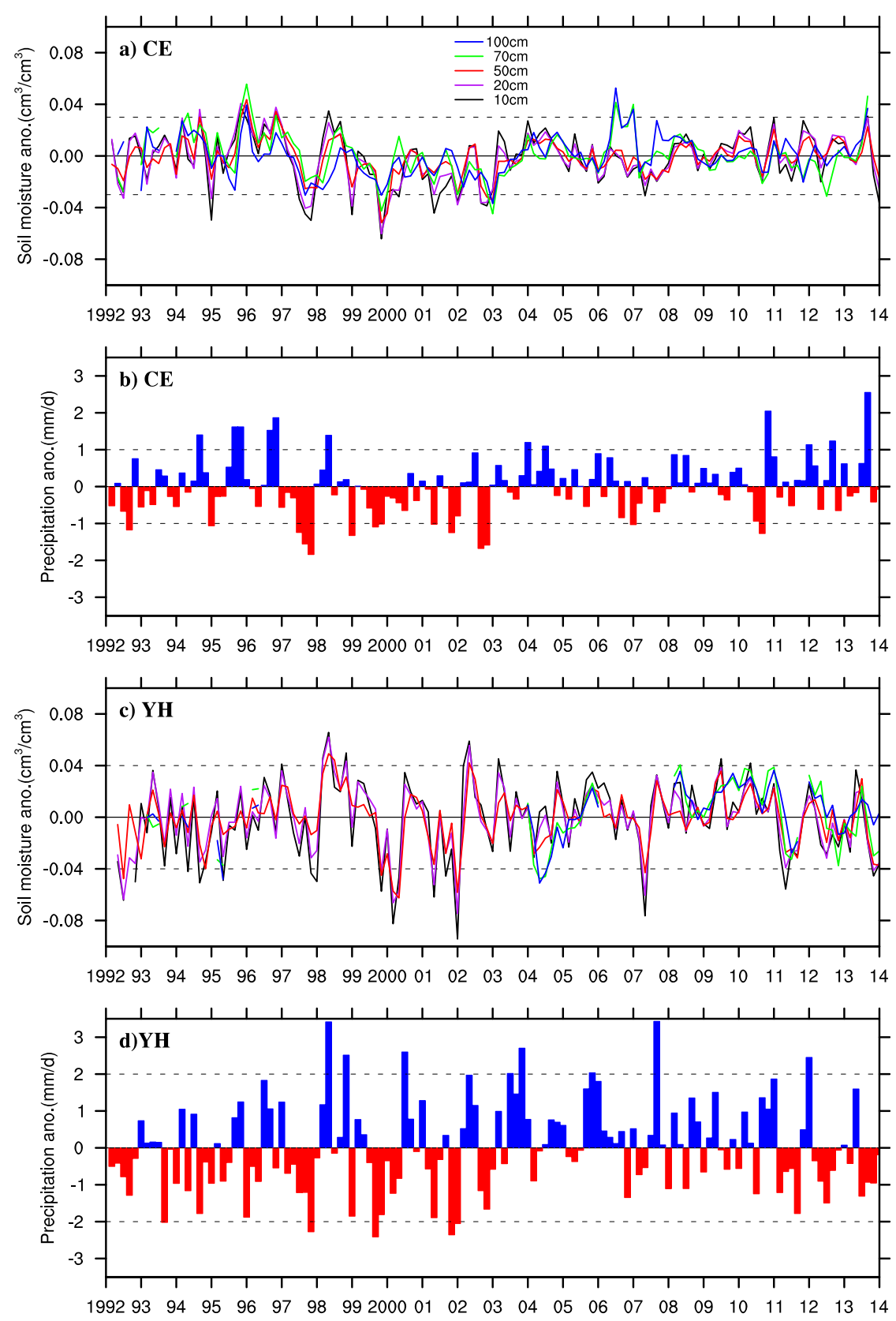

FIG. 8. Monthly time series of (a),(c) volumetric soil moisture and (b),(d) precipitation anomalies for the CE region in (a) and (b) and the $\mathrm{YH}$ region in (c) and (d). Only the data during the growing season (April-September) in each year are shown.

The relationship between Pr and SM is very poor in $\mathrm{XJ}$, where the concurrent Cross-Corr is only 0.29 at $10 \mathrm{~cm}, 0.14$ at $20 \mathrm{~cm}$, and 0.009 at $50 \mathrm{~cm}$, in which only the 10-cm Cross-Corr for the concurrent and 1-month lag passes the significance test $(p=0.05)$. In arid regions such as $\mathrm{XJ}$ and others, the arriving ground $\mathrm{Pr}$ is easily removed by the evaporation and surface runoff due to the intensive solar radiation and high albedo, and thus the water cannot be retained for long time in the soil. On the other hand, the soil texture in $\mathrm{XJ}$ consists mainly of sandy particles, and has high porosity and water conductivity (Shangguan et al. 2014; $\mathrm{Wu}$ et al. 2014). The small portion of infiltrated $\mathrm{Pr}$ amounts at the soil surface then quickly percolates into the deep soil. Thus, the antecedent Pr cannot accurately represent the SM conditions for arid regions.

The standardized precipitation index (SPI) is commonly used in the meteorological community to characterize 

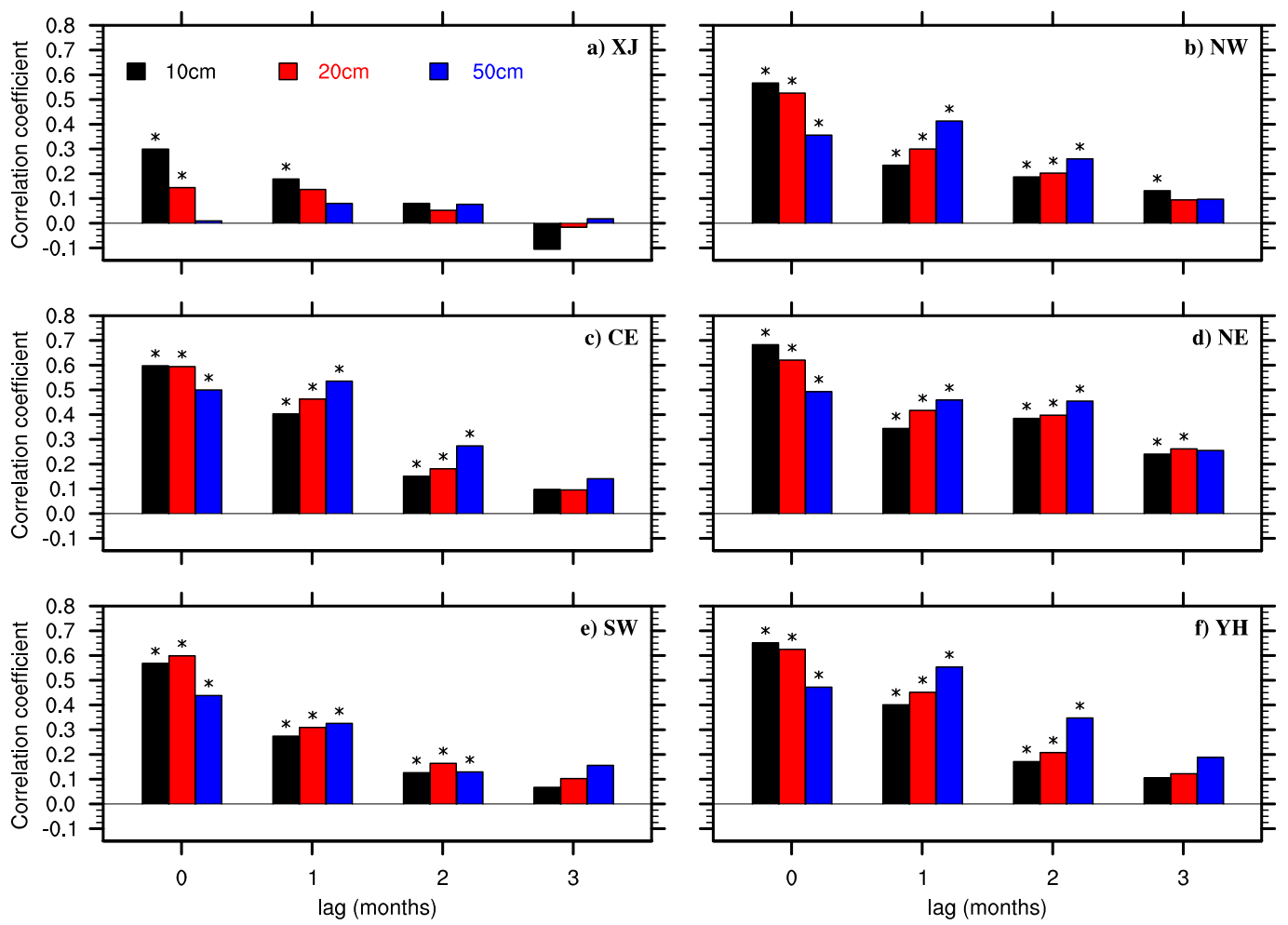

FIG. 9. Bar plots of the correlation coefficient between precipitation and soil moisture at lag times of $0,1,2$, and 3 months over six subregions for the period from 1992 to 2013. The bars with stars above indicate that correlation is significant at the $95 \%$ confidence level.

wetness and dryness, and it denotes the accumulated $\mathrm{Pr}$ anomaly for a period of time with respect to the longterm climatology mean (McKee et al. 1993). The SPI-01, SPI-03, and SPI-06 represent Pr anomaly conditions during the past 1,3 , and 6 months, respectively. Negative/positive SPI values indicate the accumulated $\mathrm{Pr}$ deficiency/abundance, which is consistent with the sign of the SM anomaly according to soil dry/wet conditions. As was mentioned in the introductory section, SPI has often been used in previous work as a proxy to represent the SM conditions (e.g., Hirschi et al. 2011; Mueller and Seneviratne 2012; Meng and Shen 2014; Wang et al. 2015; Whan et al. 2015). To further address the representation of antecedent Pr on SM anomaly, we first computed the SPI-01, SPI-03, and SPI-06 values at each station in each subregion, and then the mean CrossCorrs (Fig. 10a) and the percentage sign consistency (PSC) between the SM anomaly at $10 \mathrm{~cm}$ and the SPIs (Fig. 10b). Over five subregions except for XJ, all CrossCorrs are greater than 0.4 , and 11 of 18 Cross-Corrs are over 0.6. For four of the six subregions, the Cross-Corrs between SPI-03 and the SM anomaly are larger than they are for other two pairs, implying that SPI-03 better represents SM than the other SPIs. A larger Cross-Corr value indicates better representation of SPI on SM anomaly. At XJ, the Cross-Corrs are only 0.18, 0.28, and 0.18 for SPI-01, SPI-03, and SPI-06, respectively. Similar results are also seen in Fig. 10b in which the magnitude of PSC varies between $60 \%$ and $80 \%$, and the XJ subregion shows the smallest PSC compared to other subregions.

The above results further indicate that the antecedent Pr cannot adequately the SM over arid regions. We should bear in mind that the Pr-SM relationship is complicated and is related to other land and atmosphere processes. For instance, Wang et al. (2015) compared multidrought indices in China and indicated that precipitation-only based drought indices were less characteristic of SM conditions than the precipitationtemperature-based drought indices. Therefore, the simple Cross-Corrs of Pr-SM or SPI-SM might not fully depict the relationships between antecedent $\operatorname{Pr}$ and SM anomalies, whereas it indeed provides some preliminary and basic knowledge regarding this issue.

\section{Discussion and conclusions}

For land surface environments, climate, and measurement technique issues, in situ soil moisture measurements are very rare for many regions on the world. 

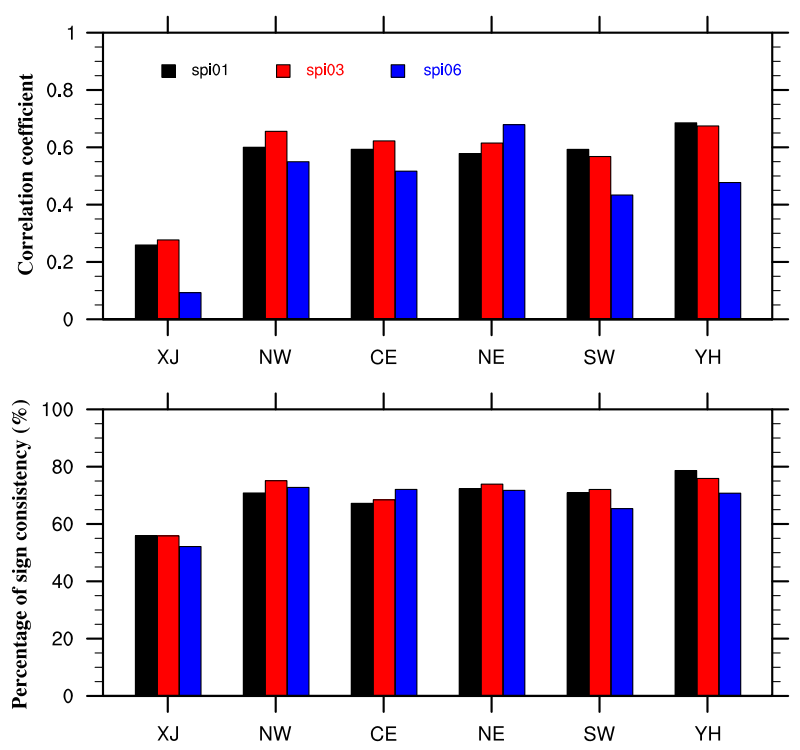

FIG. 10. Bar plots of (a) correlation coefficient and (b) the percentage sign consistency (\%) between $10-\mathrm{cm}$ soil moisture anomalies and SPI-01, SPI-03, and SPI-06 for six subregions from 1992 to 2013 .

The traditional gravimetric measurement can provide the most reliable in situ SM datasets. In China, such datasets have been used in much research (e.g., Zhang et al. 2004; Li et al. 2005; Nie et al. 2008; Wang and Zeng 2011). However, few of these datasets having complete metadata are publicly accessible (Robock et al. 2000; Dorigo et al. 2011). Moreover, the raw SM measurements from the gravimetric technique are usually recorded as the relative wetness, which does not facilitate direct use in data-model comparisons and in numerical assimilation systems. In this work, we collected and performed quality control of the raw soil moisture measurements at five soil depths $(10,20,50,70$, and $100 \mathrm{~cm}$ ) from more than 1000 stations from 1992 to 2013, and we used the field capacity and bulk density from observation-based soil texture derived soil parameter datasets; finally we converted the raw relative soil wetness to the user-convenient format, volumetric soil wetness, at the 732 stations. We have obtained more than 35000 volumetric monthly SM records at five soil depths, and they contain almost complete monthly records for the top three layers $(10,20$, and $50 \mathrm{~cm})$ during the growing season. One purpose of this work is to provide a reliable and user-convenient SM dataset from China for future applications.

We have extensively analyzed the spatiotemporal variations in SM from 1992 to 2013 in terms of their spatial distributions, seasonal and interannual variabilities, as well as their relationships with Pr. The analyses have been carried out for each station and for six subregions. The overall spatial pattern of annual SM is similar to that of $\mathrm{Pr}$, with relatively small magnitudes in arid regions such as XJ and NW, and larger magnitudes in humid regions such as in SW and HY. The interannual variations in SM are distinct and their magnitudes increase with soil depth. Compared to $\mathrm{Pr}$, the seasonal variability of SM is less distinct, showing relatively large values in spring and autumn and small values in summer. The SM Auto-Corrs at lags of 1,2, and 3 months indicate that the SM memory increases with soil depth over most subregions. By analyzing the Cross-Corr between Pr and SM anomalies at different lag times, the results indicate that the antecedent $\mathrm{Pr}$ can, to some extent, represent the SM over nonarid regions. However, the relationship over very arid areas such as $\mathrm{XJ}$, the above relationship is very poor, and the antecedent Pr is not suitable to be a proxy for SM anomalies. Further investigations on the relationship between land and atmosphere, in particular SM and $\mathrm{Pr}$, are needed to be carried on in the future.

Soil moisture controls the energy and water exchanges between land and atmosphere, and it is also very important for accurate weather forecasts and climate predictions. In general, the spatial and temporal SM characteristics were determined by both land conditions and atmospheric processes (Entin et al. 2000). Land conditions, including the land type, vegetation cover, soil texture and organic materials, are very heterogeneous within small areas, typically at scales of several square meters (Famiglietti et al. 2008). Investigations of those land factors on the SM variability require fine spacing/temporal-scale SM measurements with detailed site information, which apparently is not available in the current dataset. The gravimetric technique is a costly and inefficient method, and it cannot be used over large regions for the long term. In the future, the satellite-retrieved products and climate model simulated SM datasets could be used extensively in the research after validation (Yang et al. 2007, 2013; Liu et al. 2019). As was summarized by S.U. et al. (2014), the gravimetric technique is only one of the classics in situ SM measurements, which can be replaced with more efficient technology in the future. However, the existing measurements based on gravimetric technique are still the most accurate and valuable database (Dorigo et al. 2011) and are often treated as the standard reference for validation of other datasets such as satellite-based products and model outputs (Dorigo et al. 2015; Wang and Zeng 2011; Wang et al. 2016).

In this study, we make an effort to collect and process a user-convenient and accurate long-term SM dataset over multiple Chinese stations. Although these data do not provide full spatiotemporal coverage, they 
are still useful for future applications, such as model evaluation, satellite data validation, as well as in land surface hydrology research (e.g., Wang et al. 2016). It should be noted that since 2011, China began to install the automated instrumentation to measure soil water in many regions. The newly measured SM values from this instrumentation are reported to have biases when compared to the gravimetric thermal measurement (Wang et al. 2014), which deserves further examination, including the comparisons between traditional and automatic observations.

Acknowledgments. The work was supported by the Key project of the Ministry of Science and Technology of China (2016YFA0602401 and 2018YFC1506004) and the National Science Foundation of China (41875106). The dataset in this study is available from the authors. The authors also thank the anonymous reviewers for their helpful comments and suggestions. Qiufeng Liu at the Chinese Meteorological Administration is thanked for helping to collect raw soil moisture data.

\section{REFERENCES}

Betts, A. K., 2004: Understanding hydrometeorology using global models. Bull. Amer. Meteor. Soc., 85, 1673-1688, https:// doi.org/10.1175/BAMS-85-11-1673.

Clapp, R. W., and G. M. Hornberger, 1978: Empirical equations for some soil hydraulic properties. Water Resour. Res., 14, 601-604, https://doi.org/10.1029/WR014i004p00601.

Cosby, B. J., G. M. Hornberger, R. B. Clapp, and T. R. Ginn, 1984: A statistical exploration of the relationships of soil moisture characteristics to the physical properties of soils. Water Resour. Res., 20, 682-690, https://doi.org/10.1029/ WR020i006p00682.

Dai, Y., W. Shangguan, B. Liu, S. Fu, and G. Niu, 2013: Development of a china dataset of soil hydraulic parameters using pedotransfer functions for land surface modeling. J. Hydrometeor., 14, 869-887, https://doi.org/10.1175/JHM-D-12-0149.1.

Dirmeyer, P. A., 2011: The terrestrial segment of soil moistureclimate coupling. Geophys. Res. Lett., 38, L16702, https:// doi.org/10.1029/2011GL048268.

Dorigo, W. A., and Coauthors, 2011: The international soil moisture network: a data hosting facility for global in situ soil moisture measurements. Hydrol. Earth Syst. Sci., 15, 1675-1698, https://doi.org/10.5194/hess-15-1675-2011.

- A. Gruber, R. De Jeu, W. Wagner, T. Stacke, A. Loew, and R. Kidd, 2015: Evaluation of the ESA CCI soil moisture product using ground-based observations. Remote Sens. Environ., 162, 380-395, https://doi.org/10.1016/j.rse.2014.07.023.

Entin, J. K., A. Robock, K. Y. Vinnikov, S. E. Hollinger, S. Liu, and A. Namkhai, 2000: Temporal and spatial scales of observed soil moisture variations in the extratropics. J. Geophys. Res. 105, 11 865-11 877, https://doi.org/10.1029/2000JD900051.

Famiglietti, J. S., D. Ryu, A. A. Berg, M. Rodell, and T. J. Jackson, 2008: Field observations of soil moisture variability across scales. Water Resour. Res., 44, W01423, https://doi.org/ 10.1029/2006WR005804.
Feng, H., and M. Zhang, 2015: Global land moisture trends: Drier in dry and wetter in wet over land. Sci. Rep., 5, 18 018, https:// doi.org/10.1038/srep18018.

_ , Y. Liu, and G. Wu, 2015: Temporal variability of uncertainty in pixel-wise soil moisture: Implications for satellite validation. Remote Sens., 7, 5398-5415, https://doi.org/10.3390/ rs70505398.

Hirschi, M., and Coauthors, 2011: Observational evidence for soilmoisture impact on hot extremes in southeastern Europe. Nat. Geosci., 4, 17-21, https://doi.org/10.1038/ngeo1032.

Holmes, A., C. Rüdiger, B. Mueller, M. Hirschi, and N. Tapper, 2017: Variability of soil moisture proxies and hot days across the climate regimes of Australia. Geophys. Res. Lett., 44, 7265-7275, https://doi.org/10.1002/2017GL073793.

Koster, R. D., and M. J. Suarez, 2001: Soil moisture memory in climate models. J. Hydrometeor., 2, 558-570, https://doi.org/ 10.1175/1525-7541(2001)002<0558:SMMICM $>2.0$.CO;2.

, Y. Chang, H. Wang, and S. D. Schubert, 2016: Impacts of local soil moisture anomalies on the atmospheric circulation and on remote surface meteorological fields during boreal summer: A comprehensive analysis over North America. J. Climate, 29, 7345-7364, https://doi.org/10.1175/ JCLI-D-16-0192.1.

Li, H., A. Robock, S. Liu, X. Mo, and P. Viterbo, 2005: Evaluation of reanalysis soil moisture simulations using updated Chinese soil moisture observations. J. Hydrometeor., 6, 180-193, https://doi.org/10.1175/JHM416.1.

Liu, C., and S. Zhang, 2002: Drying up of the Yellow River: its impacts and counter-measures. Mitigation Adapt. Strategies Global Change, 7, 203-214, https://doi.org/10.1023/A: 1024408310869.

Liu, Y., Y. Liu, and W. Wang, 2019: Inter-comparison of satellite-retrieved and global land data assimilation systemsimulated soil moisture datasets for global drought analysis. Remote Sens. Environ., 220, 1-18, https://doi.org/10.1016/ j.rse.2018.10.026.

Ma, S., K. Zhu, M. Li, and Z. Ma, 2016: A comparative study of multi-source soil moisture data for China's regions (in Chinese with English abstract). Climatic Environ. Res., 21, 121-133.

Maidment, D. R., 1993: Handbook of Hydrology. McGraw-Hill Inc., $1424 \mathrm{pp}$.

McKee, T. B., N. J. Doesken, and J. Kleist, 1993: The relationship of drought frequency and duration to time scales. Proc. Eighth Conference on Applied Climatology, Anaheim, CA, Amer. Meteor. Soc., 179-184.

Meng, L., and Y. Shen, 2014: On the relationship of soil moisture and extreme temperatures in East China. Earth Interact., 18, https://doi.org/10.1175/2013EI000551.1.

Mueller, B., and S. I. Seneviratne, 2012: Hot days induced by precipitation deficits at the global scale. Proc. Natl. Acad. Sci. USA, 109, 12 398-12 403, https://doi.org/10.1073/pnas.1204330109.

Nicolai-Shaw, N., M. Hirschi, H. Mittelbach, and S. I. Seneviratne, 2015: Spatial representativeness of soil moisture using in situ, remote sensing, and land reanalysis data. J. Geophys. Res. Atmos., 120, 9955-9964, https://doi.org/10.1002/2015JD023305.

Nie, S., Y. Luo, and J. Zhu, 2008: Trends and scales of observed soil moisture variations in China. Adv. Atmos. Sci., 25, 43-58, https://doi.org/10.1007/s00376-008-0043-3.

Orth, R., and S. I. Seneviratne, 2017: Variability of soil moisture and sea surface temperatures similarly important for warmseason land climate in the community earth system model. J. Climate, 30, 2141-2162, https://doi.org/10.1175/JCLI-D15-0567.1. 
Robock, A., K. Y. Vinnikov, G. Srinivasan, J. K. Entin, S. E. Hollinger, N. A. Speranskaya, S. Liu, and A. Namkhai, 2000: The Global Soil Moisture Data Bank. Bull. Amer. Meteor. Soc., 81, 1281-1299, https://doi.org/10.1175/1520-0477(2000) $081<1281$ :TGSMDB $>2.3$.CO;2.

Seneviratne, S. I., T. Corti, E. L. Davin, M. Hirschi, E. B. Jaeger, I. Lehner, B. Orlowsky, and A. J. Teuling, 2010: Investigating soil moisture-climate interactions in a changing climate: A review. Earth Sci. Rev., 99, 125-161, https://doi.org/10.1016/ j.earscirev.2010.02.004.

Shangguan, W., and Coauthors, 2013: A China data set of soil properties for land surface modeling. J. Adv. Model. Earth Syst., 5, 212-224, https://doi.org/10.1002/jame.20026.

—, Y. Dai, Q. Duan, B. Liu, and H. Yuan, 2014: A global soil data set for earth system modeling. J. Adv. Model. Earth Syst., 6, 249-263, https://doi.org/10.1002/2013MS000293.

Shi, X., 2009: "Initial" soil moisture effects on the climate in China - A regional climate model study. J. Ocean Univ. China, 8, 111-120, https://doi.org/10.1007/s11802-009-0111-z.

S.U., S. L., D. N. Singh, and M. S. Baghini, 2014: A critical review of soil moisture measurement. Measurement, 54, 92-105, https:// doi.org/10.1016/j.measurement.2014.04.007.

Sun, C., W. Li, Z. Zhang, and J. He, 2005: Distribution and variation features of soil humidity anomaly in Huaihe River basin and its relationship with climatic anomaly (in Chinese with English abstract). J. Appl. Meteor. Sci., 16, 129-138.

van den Hurk, B., and Coauthors, 2016: LS3MIP (v1. 0) contribution to CMIP6: The Land Surface, Snow and Soil moisture Model Intercomparison Project-Aims, setup and expected outcome. Geosci. Model Dev., 9, 2809-2832, https://doi.org/ 10.5194/gmd-9-2809-2016.

Vivoni, E. R., K. Tai, and D. J. Gochis, 2009: Effects of initial soil moisture on rainfall generation and subsequent hydrologic response during the North American monsoon. J. Hydrometeor., 10, 644-664, https://doi.org/10.1175/2008JHM1069.1.

Wang, A., and X. Zeng, 2011: Sensitivities of terrestrial water cycle simulations to the variations of precipitation and air temperature in China. J. Geophys. Res., 116, D02107, https://doi.org/ 10.1029/2010JD014659.

, - - S. Shen, Q. Zeng, and R. Dickinsion, 2006: Timescales of land surface hydrology. J. Hydrometeor., 7, 868-879, https:// doi.org/10.1175/JHM527.1.

, T. Bohn, S. Mahanama, R. Koster, and D. Lettenmaier, 2009: Multimodel ensemble reconstruction of drought over the continental United States. J. Climate, 22, 2694-2712, https:// doi.org/10.1175/2008JCLI2586.1.
- D. P. Lettenmaier, and J. Sheffield, 2011: Soil moisture drought in China, 1950-2006. J. Climate, 24, 3257-3270, https:// doi.org/10.1175/2011JCLI3733.1.

_- X. Zeng, and D. Guo, 2016: Estimates of global surface hydrology and heat fluxes from the Community Land Model (CLM4.5) with four atmospheric forcing datasets. J. Hydrometeor., 17, 2493-2510, https://doi.org/10.1175/ JHM-D-16-0041.1.

Wang, H., J. Rogers, and D. Munroe, 2015: Commonly used drought indices as indicators of soil moisture in China. J. Hydrometeor., 16, 1397-1408, https://doi.org/10.1175/JHM-D-14-0076.1.

Wang, L., Y. Zhang, and L. Chen, 2014: Error analysis of automatic soil moisture observation data (in Chinese with English abstract). Mater. Sci. Technol., 42, 731-736.

Whan, K., J. Zscheischler, R. Orth, M. Shongwe, M. Rahimi, E. O. Asare, and S. I. Seneviratne, 2015: Impact of soil moisture on extreme maximum temperatures in Europe. Wea. Climate Extremes, 9, 57-67, https://doi.org/10.1016/j.wace.2015.05.001.

Wu, L., A. Wang, and Y. Sheng, 2014: Impact of soil texture on the land surface Process in China (in Chinese with English abstract). Climatic Environ. Res., 19, 559-571.

Wu, W., and R. E. Dickinson, 2004: Time scales of layer soil moisture memory in the context of land-atmosphere interaction. J. Climate, 17, 2752-2764, https://doi.org/10.1175/ 1520-0442(2004)017<2752:TSOLSM>2.0.CO;2.

Yang, K., and Coauthors, 2013: A multiscale soil moisture and freezethaw monitoring network on the third pole. Bull. Amer. Meteor Soc., 94, 1907-1916, https://doi.org/10.1175/BAMS-D-12-00203.1.

Yang, S., S. Yoo, R. Yang, K. Mitchell, H. van den Dool, and R. Higgins, 2007: Response of seasonal simulations of a regional climate model to high-frequency variability of soil moisture during the summers of 1988 and 1993. J. Hydrometeor., 8, 738757, https://doi.org/10.1175/JHM616.1.

Zeng, J., Z. Li, Q. Chen, H. Bi, J. Qiu, and P. Zou, 2015: Evaluation of remotely sensed and reanalysis soil moisture products over the Tibetan Plateau using in-situ observations. Remote Sens. Environ., 163, 91-110, https://doi.org/10.1016/j.rse.2015.03.008.

Zhang, X., X. Wu, and J. He, 2004: Vertical character of soil moisture in China (in Chinese with English abstract). Acta Meteor. Sin., 62, 52-61.

Zong, Y., and X. Chen, 2000: The 1998 flood on the Yangtze, China. Nat. Hazards, 22, 165-184, https://doi.org/10.1023/A:1008119805106.

Zreda, M., W. J. Shuttleworth, X. Zeng, C. Zweck, D. Desilets, T. Franz, and R. Rosolem, 2012: COSMOS: The COsmic-ray Soil Moisture Observing System. Hydrol. Earth Syst. Sci., 16, 4079-4099, https://doi.org/10.5194/hess-16-4079-2012. 